\title{
Response to: 'Comment on: 'Immediate IOP elevation after transscleral cyclophotocoagulation'
}

\author{
M. R. Razeghinejad ${ }^{1,2} \cdot$ Adel Hamid $^{2} \cdot$ M. H. Nowroozzadeh ${ }^{2}$
}

Received: 23 December 2017 / Accepted: 2 January 2018 / Published online: 9 March 2018

(c) The Royal College of Ophthalmologists 2018

We would like to thank Ochieng and his associates for sharing their experience regarding immediate intraocular pressure (IOP) profile after transscleral cyclophotocoagulation with 40 spots at the power of $1500 \mathrm{~mW}$ for a duration of $1500 \mathrm{~ms}$ [1]. Using distinct laser parameters, could explain the different outcomes of their study compared with ours [2]. The laser setting in our series was the recommended standard protocol [3]. The starting laser parameters were a power of $2000 \mathrm{~mW}$ for a duration of $2000 \mathrm{~ms}$, and we used 5-6 laser spots in each quadrant. The power was increased in $250 \mathrm{~mW}$ increments until an audible "pop" was heard, and then decreased in $250 \mathrm{~mW}$ steps until there was no audible "pop", then the procedure was continued and completed at that power.

As we noted [2], limited outflow facility reserve could have been a predisposing factor for IOP elevation after transscleral cyclophotocoagulation. All our patients had baseline IOP of $20 \mathrm{~mm} \mathrm{Hg}$ or more on maximally tolerated medical therapy, which indicates a poor outflow status. In Ochieng et al's report [1], three patients (8.5\%) had a baseline IOP of less than $20 \mathrm{~mm} \mathrm{Hg}$, which could be a sign of better outflow and more efficiency in handling the laser-imposed load. They also did not provide information regarding the antiglaucoma medications [1]. A study with a long-term follow up using their suggested protocol may support it as an alternative to the standard protocol.

\section{Compliance with ethical standards}

Conflict of interest The authors declare that they have no conflict of interest.

\section{References}

1. Ochieng L, Niyadurupola N, Broadway D, Eke T. Comment on: 'Immediate IOP elevation after transscleral cyclophotocoagulation' Eye (Lond). 2018; epub ahead of print https://doi.org/10.1038/ s41433-018-0034-2.

2. Razeghinejad MR, Hamid A, Nowroozzadeh MH. Immediate IOP elevation after transscleral cyclophotocoagulation. Eye (Lond). 2017;31(8):1249-50.

3. Pastor SA, Singh K, Lee DA, Juzych MS, Lin SC, Netland PA, et al. Cyclophotocoagulation: a report by the American Academy of Ophthalmology. Ophthalmology. 2001;108(11):2130-8.
M. H. Nowroozzadeh

nowroozzadeh@hotmail.com

1 Glaucoma Service, Wills Eye Hospital, Philadelphia, PA, USA

2 Poostchi Eye Research Center, Shiraz University of Medical Sciences, Shiraz, Iran 